\title{
Are Data Caps Reasonable?
}

\author{
Scott Jordan \\ Department of Computer Science \\ University of California, Irvine \\ Irvine, CA 92697 \\ sjordan@uci.edu
}

\begin{abstract}
We discuss how data caps may be evaluated under the FCC's 2015 Open Internet Order. We find that heavy-users caps on mobile broadband service are likely to satisfy the Order's rules, that profit-maximizing caps on mobile broadband service may or may not satisfy the rules, and that caps on fixed broadband service are unlikely to satisfy the rules.

\section{CCS CONCEPTS}

- Networks $\rightarrow$ Network algorithms $\rightarrow$ Network economics • Social and professional topics $\rightarrow$ Computing / technology policy $\rightarrow$ Government technology policy $\rightarrow$ Governmental regulations
\end{abstract}

\section{ADDITIONAL KEYWORDS AND PHRASES}

Net neutrality, Open Internet

\section{ACM Reference format:}

Scott Jordan. 2018. Proceedings of the $13^{\text {th }}$ Workshop on the Economics of Networks, Systems, and Computation, Irvine, California, USA, June 2018 (NetEcon'18), 6 pages. https://doi.org/10.1145/3230654.3230655

\section{INTRODUCTION}

Starting in 2010, most mobile broadband Internet access service providers in the United States instituted monthly data caps in most of their service plans. In addition, many fixed broadband Internet access service providers (often referred to as Internet Service Providers) have instituted monthly data caps in many of their service plans. The United States Government Accountability Office (GAO) found in 2014 that the four largest mobile broadband providers and seven of the thirteen largest fixed broadband providers used monthly data caps [1]. Subscribers whose usage exceeds a data cap are typically either subjected to overage charges or reduced speeds. Recently, many mobile broadband providers re-introduced plans that they brand as "unlimited". However, those "unlimited" plans usually throttle users whose monthly usage exceeds a threshold. ${ }^{1}$

Permission to make digital or hard copies of all or part of this work for personal or classroom use is granted without fee provided that copies are not made or distributed for profit or commercial advantage and that copies bear this notice and the full citation on the first page. Copyrights for components of this work owned by others than the author(s) must be honored. Abstracting with credit is permitted. To copy otherwise, or republish, to post on servers or to redistribute to lists, requires prior specific permission and/or a fee. Request permissions from Permissions@acm.org. NetEcon '18, June 18, 2018, Irvine, CA, USA

(C) 2018 Copyright is held by the owner/author(s). Publication rights licensed to ACM.

ACM 978-1-4503-5916-0/18/06 ..\$15.00
The use of monthly data caps by broadband Internet access service providers has been an issue of public policy debate ever since their introduction. The Federal Communications Commission's (FCC) Open Internet Advisory Committee (FCC OIAC) reported in 2013 on policy issues that arise from data caps [2]. The Committee's report discussed often conflicting perceptions of various stakeholders over fairness between light and heavy users; correlation between monthly usage and peak period usage; the role of data caps in managing congestion, managing network growth, and as a price discrimination tool; and competition issues.

In 2015, the FCC passed the 2015 Open Internet Order [3]. The Order included a general conduct rule that provided protection against broadband provider practices that harm Internet openness, and stated that data caps would be addressed under that rule. $^{2}$ In 2017, the FCC repealed most of the Open Internet rules [4], including the general conduct rule. However, this repeal is currently being litigated, and the repeal may be reversed.

In Section 2, we provide an overview of how data caps may be evaluated under the 2015 Open Internet Order. In Section III, we find that data caps intended to recover the cost of heavy usage are likely to qualify as reasonable network management if and only if there is a sufficient correlation between monthly usage and a user's contribution to congestion.

In Sections 4-6, for data caps that don't qualify as reasonable network management, we analyze the pertinent factors the FCC would use in assessing whether a data cap satisfies the Order's general conduct rule: competitive effects; effect on innovation, investment, or broadband deployment; and end-user control.

We find that a mobile broadband heavy-users cap is likely to satisfy the general conduct rule due to positive effects on consumer choice and on innovation, investment, and broadband deployment, but that a fixed broadband heavy-users cap is likely to violate the general conduct rule due to negative effects on consumer choice and on innovation, investment, and broadband deployment. We also find that a mobile broadband profitmaximizing cap might satisfy the general conduct rule, but only if the benefits from increasing broadband provider investment and deployment outweigh the harms from disadvantaging an edge provider's ability to offer high-volume content and from corresponding reduced edge provider investment and innovation.

https://doi.org/10.1145/3230654.3230655

${ }^{1}$ Since the frequency, duration, and effect of this throttling remains largely unknown to the public, it remains unclear whether such "unlimited" plans bear a closer resemblance to plans with data caps than to unlimited plans without throttling.

${ }^{2}$ The 2015 Open Internet Order also includes no-throttling, no-blocking, no-paidprioritization, and transparency rules. 
A fixed broadband profit-maximizing cap is likely to violate the general conduct rule, due to negative effects on consumer choice, on competition, and on innovation, investment, and broadband deployment. Finally, data caps whose purpose is to protect incumbent pay-television services are similarly likely to violate the general conduct rule.

\section{DATA CAPS UNDER THE 2015 OPEN INTERNET ORDER}

The 2015 Open Internet Order does not pass judgement on whether data caps would violate any its rules, but it does discuss how they would be judged. The Order notes that data caps "may benefit consumers by offering them more choices over a greater range of service options, and, for mobile broadband networks, such plans are the industry norm today, in part reflecting the different capacity issues on mobile networks" [3, para. 153]. The Order also notes that "[c]onversely, some commenters have expressed concern that such practices can potentially be used by broadband providers to disadvantage competing over-the-top providers." It then declares that any concerns about data caps will be addressed on a case-by-case basis under the general conduct rule in the Order.

In addition, data caps are covered by the Order's transparency rule. The transparency rule requires that broadband Internet access service providers "publicly disclose accurate information regarding the network management practices, performance, and commercial terms of its broadband Internet access services sufficient for consumers to make informed choices regarding use of such services and for content, application, service, and device providers to develop, market, and maintain Internet offerings" [3, para. 54]. The 2015 Open Internet Order clarifies that the required disclosures include "any data caps or allowances that are a part of the plan the consumer is purchasing, as well as the consequences of exceeding the cap or allowance" [3, para. 164]. In addition, when a network practice is applied to traffic associated with a particular user or user group, the disclosures must include "the purpose of the practice, which users or data plans may be affected, the triggers that activate the use of the practice, the types of traffic that are subject to the practice, and the practice's likely effects on end users' experiences" [3, para. 169].

These requirements may be particularly important for mobile broadband plans that are branded as "unlimited". If such plans throttle users whose monthly usage exceeds a threshold (as most do), then the transparency rule requires that disclosures include the likely effect of such throttling on end user's experiences. Many such disclosures state only that throttling of heavy users may result in decreased performance such as reduced speeds and increased latency, but do not disclose anything about the frequency or severity of such decreased performance. It is unlikely that such limited disclosures could be reasonably construed as providing information sufficient for consumers to make informed choices regarding use of mobile broadband Internet access service.

The general conduct rule provides protection against broadband provider practices that harm Internet openness. Specifically, the rule states that broadband Internet access service providers shall not "unreasonably interfere with or unreasonably disadvantage (i) end users' ability to select, access, and use broadband Internet access service or the lawful Internet content, applications, services, or devices of their choice, or (ii) edge providers' ability to make lawful content, applications, services, or devices available to end users" [3, para. 136]. The rule allows an exception for "reasonable network management", which is defined and discussed below.

The Order sets out a non-exhaustive list of factors to be used in assessing a network practice under the general conduct rule [3, paras. 138-145]. The most pertinent factors for evaluation of data caps are: competitive effects; effect on innovation, investment, or broadband deployment; and end-user control. Each of these factors is discussed below.

\section{REASONABLE NETWORK MANAGEMENT}

Network practices that qualify as reasonable network management do not violate the general conduct rule, regardless of the other factors for evaluation. Since proponents of data caps often propose that the primary purpose of data caps is to manage network congestion, it is worthwhile considering whether they may qualify as reasonable network management.

The Order defines the term "network management practice" as "a practice that has a primarily technical network management justification, but does not include other business practices" [3, para. 215]. It then states that "[a] network management practice is reasonable if it is primarily used for and tailored to achieving a legitimate network management purpose, taking into account the particular network architecture and technology of the broadband Internet access service."

The first question is thus whether data caps have a primarily technical network management justification. The answer critically depends on the purpose and size of the data cap. If the size of a data cap and the corresponding overage charge is set to recover the cost associated with heavy users, then we call such a data cap a "heavy-users cap". In contrast, if a data cap and the corresponding overage charge is set to maximize the broadband provider's profit, then we call such a data cap a "profitmaximizing cap".

Thus, the FCC would first need to determine the nature of the cap. Network costs can be categorized into a fixed cost that does not depend on either the number of subscribers or the traffic, a variable access cost that depends on the number of subscribers but not the traffic, and a variable capacity cost that depends on the capacity of the network [5]. Although proponents and opponents disagree about whether the fixed cost should be allocated on the basis of monthly usage, both sides agree that the fixed costs and variable access costs are substantial, and that they should be reflected in the monthly service price (excluding any overage charges).

A data cap could thus be considered as a heavy-users cap only if the overage charge (in $\$ / \mathrm{GB}$ ) is substantially less than the average price per unit volume of the service tier (i.e. the monthly service price divided by the data cap, in $\$ / G B$ ). The data caps examined in the academic literature all have overage charges that exceed the average price per unit volume of the service tier, and thus are not heavy-users caps [6]-[9].

Profit-maximizing caps, by their definition, have a primarily business justification. The Order specifically notes that "a practice that permits different levels of network access for similarly 
situated users based solely on the particular plan to which the user has subscribed" does not qualify as reasonable network management [3, para. 216]. Profit-maximizing caps thus must be evaluated under the factors used in assessing a network practice under the general conduct rule. Data caps whose purpose is to protect incumbent pay-television services would similarly not qualify as reasonable network management.

In contrast, proponents argue that when data caps and overage charges are set to recover the cost associated with heavy users, namely heavy-users caps, the primary purpose is to manage congestion. Furthermore, the 2010 Open Internet Order explicitly states that alleviating congestion is a technical network management justification [10, para. 82]. The question thus boils down to whether economically regulating monthly usage reduces congestion. Proponents assert it does, while opponents often claim that the two are unrelated.

In the short-term reduced usage from newly added heavy-users caps will reduce congestion, and in the long-term broadband providers will augment network capacity based on the desired performance of the dominant applications, returning congestion to the desired level [5]. The short-term benefit is likely sufficient to determine that heavy-users caps have a primarily technical management justification. Thus, heavy-users caps could likely be evaluated to determine whether they are reasonable network management.

For heavy-users caps, the next question is thus whether they are "primarily used for and tailored to achieving" a reduction in congestion. The question of whether heavy-users caps are "tailored to" alleviating congestion focusses on whether they are a reasonable method for doing so. Proponents argue that data caps are an efficient and effective means for alleviating congestion. Opponents argue that data caps are an ineffective means for alleviating congestion, pointing toward the weak correlation between monthly usage and peak-period usage and arguing for more tailored methods.

The academic literature shows that there is a strong correlation between heavy monthly users and heavy peak usage period users. However, the relationship between monthly usage and peak period usage is not linear, and thus the correlation between monthly usage and a user's contribution to congestion is only moderate.

There are reasonable arguments on both sides here. The Order states that "[i]n evaluating congestion management practices, ... we will also consider whether the practice is triggered only during times of congestion and whether it is based on a user's demand during the period of congestion" [3, para. 220]. Data caps fail both parts of this test. On the other hand, a broadband provider need not show that data caps are the most tailored method for alleviating congestion. ${ }^{3}$ Thus, it is unclear whether heavy-users caps would be judged as sufficiently tailored.

If heavy-users caps are judged as sufficient tailored, the only remaining question is whether heavy-users caps are "primarily used for" alleviating congestion. Heavy-users caps result in a transfer from the consumer surplus of heavy users to broadband

\footnotetext{
${ }^{3}$ The FCC rejected a proposal that "network management techniques ... would only be reasonable if they were used temporarily, for exceptional circumstances, and have a proportionate impact to solve a targeted problem." [3, para. 222].
}

provider profit [5]. Thus, there is a benefit to the broadband provider other than reducing congestion. However, since the transfer of consumer surplus is directly related to the increase in fairness, a strong argument can be made that the primary use of heavy-users caps is to alleviate congestion.

In summary, good arguments can be made on both sides of whether heavy-users caps satisfy the definition of reasonable network management, and thus would not violate the general conduct standard. However, profit-maximizing caps would not qualify as reasonable network management, and thus must be evaluated under the other factors guiding application of the general conduct rule.

\section{COMPETITIVE EFFECTS}

In laying out the landscape for the competitive effects factor, the Order discusses both the potential incentive and potential ability of a broadband provider to use network practices that have anticompetitive effects.

With respect to incentive, the Order notes that "broadband providers have incentives to interfere with and disadvantage the operation of third-party Internet-based services that compete with the providers' own services" [3, para. 140]. More specifically, the FCC stated in the 2010 Open Internet Order that "broadband providers have incentives to interfere with the operation of thirdparty Internet-based services that compete with the providers' revenue-generating telephony and/or pay-television services" and that " $[\mathrm{b}] \mathrm{y}$ interfering with the transmission of third parties' Internet-based services or raising the cost of online delivery for particular edge providers, telephone and cable companies can make those services less attractive to subscribers in comparison to their own offerings" [10, para. 22].

The FCC could analyze whether a broadband provider's purpose in using data caps coincides with such an anticompetitive incentive. Proponents often argue that the principal purpose of data caps is to manage congestion and increase fairness, and that these purposes are in no way anti-competitive. Opponents often argue that the principal purpose of data caps is to increase profit and/or to retain subscribers to the broadband providers' pay-television services.

Heavy-users caps do not have anti-competitive incentives. Profit-maximizing caps do not have anti-competitive incentives, but may have anti-competitive effects, as discussed further below. Caps intended to protect incumbent pay-television services clearly have anti-competitive incentives. As discussed above, the FCC could analyze the purpose of a data cap by examining the ratio of the overage charge to the average price per unit volume of the service tier.

More likely, however, the FCC would place the emphasis not on the incentive but on the exercising of an ability. The Order notes that "[p]ractices that have anti-competitive effects in the market for applications, services, content, or devices would likely unreasonably interfere with or unreasonably disadvantage edge providers' ability to reach consumers in ways that would have a dampening effect on innovation, interrupting the virtuous cycle" [3, para. 140]. The Order also specially notes that "[d]ata caps or allowances, which limit the amount and type of content users access online, can have a role in providing consumers options and differentiating services in the marketplace, but they also can 
negatively influence customer behavior and the development of new applications" [3, para. 82].

It is well established in the literature that data caps may influence customer behavior, but proponents and opponents differ in their view of whether such influence is positive or negative. Similarly, proponents and opponents differ in their view of whether data caps negatively influence the development of new applications. Fortunately, the general conduct rule states more specific tests, and separately considers the effect of a network practice on end users and on edge providers.

With respect to edge providers, the question is whether a specific data cap unreasonably interferes with or unreasonably disadvantages an edge provider's ability to make lawful content, applications, services, or devices available to end users. The Order states that "[p]ractices that have anti-competitive effects in the market for applications, services, content, or devices would likely unreasonably interfere with or unreasonably disadvantage edge providers' ability to reach consumers" [3, para. 140].

Data caps clearly interfere with or disadvantage an edge provider's ability to offer high-volume content. The question is whether this inference or disadvantage is unreasonable. Here, the comparison must be between a broadband provider's own nonbroadband services and the high-volume edge provider services that compete with them. Since broadband providers must cover the capacity cost of their non-broadband services, charging the broadband user overage fees that correspond to the cost of heavy usage does not disadvantage competing over-the-top services. Hence, heavy-users caps do not unreasonably interfere with or disadvantage an edge provider's ability to offer high-volume content.

In contrast, because profit-maximizing caps do more than recover cost associated with usage, they must be analyzed for potential anti-competitive effects. Hard caps would clearly have anti-competitive effects upon competing over-the-top video providers. Thus, there is a strong argument that profit-maximizing caps may indeed disadvantage an edge provider's ability to offer high-volume content. Similarly, data caps intended to protect a broadband provider's incumbent pay-television services would disadvantage an edge provider's ability to offer high-volume content.

With respect to end users, the question is whether a specific data cap unreasonably interferes with or unreasonably disadvantages an end user's ability to select, access, and use broadband Internet access service or the lawful Internet content, applications, services, or devices of their choice. The Order states that "anticompetitive practices are likely to harm consumers' and edge providers' ability to use broadband Internet access service to reach one another" [3, para. 140]. The analysis of the effect on an end user's ability thus is similar to the effect on an edge provider, since anticompetitive practices would affect an end user through a diminishing of applications available.

\section{EFFECT ON INNOVATION, INVESTMENT, OR BROADBAND DEPLOYMENT}

This factor focusses on what the FCC calls the "virtuous [cycle] of innovation in which new uses of the network-including new content, applications, services, and devices - lead to increased end-user demand for broadband, which drives network improvements, which in turn lead to further innovative network uses" [10, para. 77]. In applying this factor, the Order states that "practices that stifle innovation, investment, or broadband deployment would likely unreasonably interfere with or unreasonably disadvantage end users' or edge providers' use of the Internet" [3, para. 142].

Proponents argue that data caps recover cost in order to fund incremental network capacity. Opponents express doubt that data caps impact network capacity. In addition, opponents express concern that data caps impede innovation and investment by edge providers.

Consider investment by broadband providers. The use of data caps by mobile broadband providers will result in increased network capacity, but their use by fixed broadband providers is unlikely to result in increased network capacity [5].

Next consider broadband deployment. The use of heavy-users caps by fixed broadband providers is unlikely to significantly affect overall subscription, the use of profit-maximizing caps by fixed broadband providers is likely to reduce overall subscription, and the use of either type of data cap by mobile broadband providers will result in increased overall subscription [5].

However, innovation and investment include both that by broadband providers and that by edge providers, and thus the effect of data caps on broadband providers and on edge providers must both be considered. As discussed above, profit-maximizing caps interfere with or disadvantage an edge provider's ability to offer high-volume content, and hence reduce innovation and investment by such edge providers.

In summary, a fixed broadband provider's use of heavy-users caps is unlikely to significantly affect investment, innovation, or broadband deployment; but their use of profit-maximizing caps is likely to reduce overall investment, innovation, and broadband deployment. A mobile broadband provider's use of heavy-users caps is likely to increase overall investment, innovation, and broadband deployment. Finally, mobile broadband provider's use of profit-maximizing caps is likely to increase broadband provider investment and deployment, but reduce edge provider investment and innovation; the overall effect is indeterminate.

\section{END-USER CONTROL}

The Order states that "[a] practice that allows end-user control and is consistent with promoting consumer choice is less likely to unreasonably interfere with or cause an unreasonable

disadvantage affecting the end user's ability to use the Internet as he or she sees fit" [3], para. 139]. There are two elements to user choice pertinent to data caps: choice between service plans and choice in how to use a service plan.

With respect to user choice between service plans, proponents see data caps as a form of second-degree price discrimination. They are thus likely to argue that data caps allow for increased consumer choice among a more highly differentiated set of broadband service plans.

This is true for mobile broadband plans, which are unlikely to be otherwise differentiated. However, for fixed broadband Internet access service that is already differentiated by download and upload speeds, it is unlikely that the addition of data caps provides any significant increase in differentiation. Fixed broadband providers do not currently offer, for instance, multiple 
plans with the same speed but different data caps. Furthermore, if data caps resulted in increased consumer choice, then one would expect to see increased overall subscription and increased consumer surplus. However, no such effects are likely when data caps are used in fixed broadband service [5].

With respect to user choice in how to use a service plan, all forms of data caps reduce heavy usage [5]. Thus, data caps clearly interfere with or disadvantage an end user's ability to use highvolume Internet content. The question is whether this interference or disadvantage is unreasonable.

Heavy-users caps reflect the cost of that usage, and hence do not unreasonably disadvantage an end user's ability to use highvolume Internet content. In contrast, profit-maximizing caps have lower data caps and higher overage charges than necessary to recover the cost of heavy usage, and thus the question of reasonableness remains. Here, proponents argue profitmaximizing caps provide a form of second-degree price discrimination that will usually increase consumer surplus, and thus presumably not be unreasonable. However, profitmaximizing caps reduce consumer surplus compared to heavyusers caps [5]. Thus, there is a strong argument that profitmaximizing caps may indeed unreasonably disadvantage an end user's ability to use high-volume Internet content.

\section{CONCLUSIONS}

If the 2015 Open Internet Order is reinstated, data caps could be evaluated under the Order's general conduct rule.

A complainant may claim that data caps are not primarily intended to manage congestion and thus do not qualify as reasonable network management; harm competition in information services between broadband providers and edge providers; reduce innovation and investment by edge providers; and leave the consumer with few choices to access high-volume Internet content.

In contrast, broadband providers are likely to claim that data caps are an effective and efficient means of managing congestion, and thus fall under the reasonable network management exception to the rule. If such a practice does not qualify as reasonable network management, broadband providers are likely to claim that data caps increase fairness and are not anti-competitive; result in additional investment, innovation, and broadband deployment by broadband providers; do not impede edge provider investment and innovation; and are subject to consumer choice.

We found that the validity of these claims depends on whether a data cap is a heavy-users cap or a profit-maximizing cap. The nature of the cap must therefore be determined, likely by comparing the overage charge per unit volume to the average price per unit volume of the service tier.

Heavy-users caps are likely to be determined to have a primarily technical management justification, namely alleviating congestion.

There are reasonable arguments on both sides of whether a heavy-users cap is primarily used for and tailored to achieving a reduction in congestion. On the upside, there is a strong correlation between heavy monthly users and heavy peak usage period users, and heavy-users caps increase fairness. On the downside, the correlation between correlation between monthly usage and a user's contribution to congestion is only moderate and thus not directly based on a user's demand during the period of congestion. Furthermore, heavy-users caps are not triggered only during times of congestion. We expect that determination of whether a heavy-users cap qualifies as reasonable network management would turn on the strength of the correlation between monthly usage and a user's contribution to congestion.

If a heavy-users cap does not qualify as reasonable network management, then it must be considered under the factors used in assessing a network practice under the general conduct rule.

Heavy-users caps do not have anti-competitive incentives, and do not unreasonably interfere with or disadvantage an edge provider's ability to offer high-volume content. Thus, there are neither positive nor negative competitive effects.

The effect of a heavy-users cap on innovation, investment, and broadband deployment is different for fixed and for mobile broadband service. The use of a heavy-users cap by a fixed broadband provider is unlikely to result in increased network capacity and is unlikely to significantly affect overall subscription, and is thus unlikely to significantly affect investment, innovation, or broadband deployment. In contrast, the use of a heavy-users cap by a mobile broadband provider will result in increased network capacity and in increased overall subscription, and is thus likely to increase overall investment, innovation, and broadband deployment. Furthermore, heavy-users caps in fixed broadband service are unlikely to increase consumer choice when service is already differentiated by speed, whereas their use in mobile broadband service will increase consumer choice compared to undifferentiated unlimited plans.

In summary, a heavy-users cap is likely to qualify as reasonable network management if it can be shown that there is sufficient correlation between monthly usage and a user's contribution to congestion. If it does not qualify, a mobile broadband heavy-users cap is likely to satisfy the general conduct rule, due to positive effects on consumer choice and on innovation, investment, and broadband deployment. However, a fixed broadband heavy-users cap is likely to violate the general conduct rule, due to negative effects on consumer choice and on innovation, investment, and broadband deployment.

The analysis of profit-maximizing caps and of caps whose purpose is to protect incumbent pay-television services is very different. First, a cap of either sort would not qualify as reasonable network management, because it has a primarily business justification.

The analysis thus entirely focusses on the factors used in assessing a network practice under the general conduct rule. Profit-maximizing caps do not have anti-competitive incentives, but they are likely to have anti-competitive effects by disadvantaging an edge provider's ability to offer high-volume content. Caps whose purpose is to protect incumbent paytelevision services have both anti-competitive incentives and similar anti-competitive effects.

The use of a profit-maximizing cap by a fixed broadband provider is unlikely to result in increased network capacity, is likely to reduce overall subscription, and is likely to interfere with or disadvantage an edge provider's ability to offer high-volume content, and is thus likely to reduce investment, innovation, or broadband deployment. In contrast, mobile broadband provider's use of profit-maximizing caps is likely to increase broadband provider investment and deployment, but reduce edge provider 
investment and innovation, and these two effects must be compared. Furthermore, profit-maximizing caps in fixed broadband service are unlikely to increase consumer choice when service is already differentiated by speed, whereas their use in mobile broadband service will increase consumer choice compared to undifferentiated unlimited plans.

In summary, neither profit-maximizing caps nor caps whose purpose is to protect incumbent pay-television services will qualify as reasonable network management. A mobile broadband profit-maximizing cap might satisfy the general conduct rule, but only if the benefits from increasing broadband provider investment and deployment outweigh the harms from disadvantaging an edge provider's ability to offer high-volume content and from corresponding reduced edge provider investment and innovation. A fixed broadband profit-maximizing cap is likely to violate the general conduct rule, due to negative effects on consumer choice, on competition, and on innovation, investment, and broadband deployment. Data caps whose purpose is to protect incumbent pay-television services are similarly likely to violate the general conduct rule.

\section{REFERENCES}

[1] United States Government Accountability Office, "Broadband Internet: FCC Should Track the Application of Fixed Internet Usage-Based Pricing and Help Improve Consumer Education," GAO-15-108, November 2014,

http://www.gao.gov/products/GAO-15-108.

[2] Federal Communications Commission Open Internet Advisory Committee, "Policy Issues in Data Caps and Usage-Based Pricing," August 20, 2013,

https://transition.fcc.gov/cgb/oiac/Economic-Impacts.pdf.

[3] Federal Communications Commission, Protecting and Promoting the Open Internet, Report and Order on Remand, Declaratory Ruling, and Order, 30 FCC Rcd 5601 (2015), https://apps.fcc.gov/edocs public/attachmatch/FCC-15-24A1.pdf. [4] Federal Communications Commission, Restoring Internet Freedom, Declaratory Ruling, Report and Order, and Order, 33 FCC Rcd [page number to be added when available] (2018), https://apps.fcc.gov/edocs_public/attachmatch/FCC-17-166A1.pdf. [5] S. Jordan, "The Effects of Broadband Data Caps: A Critical Survey," Telecommunications Policy Research Conference (TPRC), 2017, https://papers.ssrn.com/sol3/papers.cfm?abstract id=2937976.

[6] K. Fukuda, H. Asai, and K. Nagami, "Tracking the Evolution and Diversity in Network Usage of Smartphones," Internet Measurement Conference, 2015, http://dl.acm.org/citation.cfm?id=2815697.

[7] J.B. Malone, J.L. Turner, and J.W. Williams, "Do Three-part Tariffs Improve Efficiency in Residential Broadband Networks?," Telecommunications Policy, vol. 38 , no. 11,

[8] A. Nevo, J.L. Turner, and J.W. Williams, "Usage-Based Pricing and Demand for Residential Broadband," Econometrica, vol. 84 no. 2, March 2016, http://onlinelibrary.wiley.com/doi/10.3982/ECTA11927/abstract.

[9] X. Wang, R.T.B. Ma, and Y. Xu, "The Role of Data Cap in Optimal Two-part Network Pricing," International Conference on World Wide Web, 2015, http://dl.acm.org/citation.cfm?id=2741129, 1224-1227.

[10] Federal Communications Commission, Preserving the Open Internet, Report and Order, $25 \quad$ FCC $\quad$ Rcd $17905 \quad$ (2010), https://apps.fcc.gov/edocs_public/attachmatch/FCC-10-201A1_Rcd.pdf. 